\title{
Acute Double Blind Trial of a New Anti-anginal Drug: Molsidomine
}

\author{
S. Guerchicoff, A. Vazquez, H. Kunik, S. Drajer, and F. Díaz \\ Cardiodinámica, Buenos Aires, Argentina
}

Europ. J. clin. Pharmacol. 13, 247-250 (1978)

The legends under Figure 2 and Figure 3 on page 249 were erroneously reversed. The legend under Figure 2 should have appeared under Figure 3 and the legend under Figure 3 should have appeared under Figure 2.

\section{Information}

International Symposium on

\section{Methods in Clinical Pharmacology}

May 7-8, 1979, Frankfurt/Main, Airport Hotel

\section{Preliminary Program}

Monday $7^{\text {th }}$ May 1979

Elimination of drug metabolites in liver diseases, E. Richter, Würzburg

Liver function tests and drug elimination, U. Klotz, Stuttgart Drug monitoring in small samples of bodyfluids, T. B. Vree, Nijmegen

Model substrates in assessment of drug metabolism in Man., M. D. Rawlins, Newcastle

Evaluation of non-linear serum concentration-dose relationship in phenytoin therapy, P. W. Mullen, Manchester

Amino-glycoside antibiotics-Problems and Methods, F. Follath, Basel

Individual pharmacokinetic parameters in patients on long term treatment, K.-O. Haustein, Erfurt

Drug use and drug disposition in old age, I. H. Stevenson, Dundee Verapamil plasma concentrations and therapeutic responses, B. Woodcock, Frankfurt
Tuesday $8^{\text {th }}$ May 1979

Mode of action of calcium antagonists on vascular smooth muscle, A. H. Weston, Manchester

Simultaneous modelling of pharmacokinetics and pharmacodynamics, B. Whiting, Glasgow

Patient selection in clinical pharmacological studies, R. Gugler, Bonn

Prospective versus epicritical studies on the variance of digoxin plasma levels, N. Heinz, Hamburg

Cardiac glycosides and atrial fibrillation, G. E. Mawer, Manchester

Protein binding and pharmacokinetics of propranolol, J.-P. Tillement, Paris

Micro-determination of Noradrenaline, Adrenaline, Dopamine in body-fluids, R. Kirsten, Frankfurt

Kinetic analysis of pharmacological responses, R. L. Galeazzi, Bern

Methods in Protein binding studies, W. E. Lindup, Liverpool

\section{Other Speakers will Include}

D. D. Breimer, Leiden; G. R. Daniel, London; Fowler, London; G. Aronson, Oxford; Tucker, Sheffield; Schlepper, Leuwen; F. Sjoqvist, Sweden.

\section{Applications Invited for a Poster Exhibition:}

Title and abstracts, 100 words (to be published) to be received by $6^{\text {th }}$ April 1979 on the poster registration form, obtainable from Dr. Woodcock at the address below.

All correspondence and enquiries to Dr. B. G. Woodcock, Klinische Pharmacologie, Klinikum der J. W. Goethe-Universität Frankfurt, Sandhofstraße Haus 74, D-6000 Frankfurt/Main 70, Tel.: 0611/6301-7619; -7618; -7617, Federal Republic of Germany

Second Postgraduate Course on

\section{Methods in Clinical Pharmacology}

November 18-24, 1979

organized by the Department of Clinical Pharmacology, University of Berne, Switzerland

For further information:

Johannes Bircher, M. D., Department of Clinical Pharmacology, CH-3010 Bern, Switzerland 